\title{
Problematização e representação da memória no espetáculo Cidade Submersa
}

Jorge Peloso de Azevedo* e Marília Gabriela Amorim Donoso**

O teatro como arte que implica repetição desde sua criação e na sua representação - num movimento incessante de reavivar ações cênicas criadas em um tempo anterior ao de sua realização frente ao público - caracteriza-se como uma arte já profundamente ligada à memória. Porém, em nossa trajetória como grupo de teatro, a memória tornou-se um dos eixos fundamentais de pesquisa e trabalho do IMPULSO Coletivo'. Ela, a memória, determinou o campo temático de nossa primeira criação por ser um importante elemento para processos de construção da identidade em um contexto urbano em constante transformação.

A partir dessa delimitação foi realizado o projeto "Desassossego - suas outras memórias" que durou mais de dois anos (2008/2010) e culminou com a criação e temporada da peça Cidade Submersa. A maior parte do projeto "Desassossego" foi desenvolvida na Vila Itororó, vila histórica da década de 1920, localizada no bairro da Bela Vista, centro de São Paulo. Construída com função de moradia, posteriormente tombada pelo Condephaat ${ }^{2}$, a Vila vem sendo alvo de controversos projetos ditos de requalificação, desde a década de 1970, os quais têm como objetivo transformá-la em centro cultural. Conhecemos Vila Itororó no final de 2008 , quando era habitada por cerca de 80 famílias que vinham sendo ameaçadas de despejo desde 2006, quando a Vila foi decretada como espaço de utilidade pública pela Secretaria Municipal de Cultura de São Paulo, para a implementação do já citado projeto cultural - sem prever a presença dos moradores nesse empreendimento. O despejo se concretizou no final de $2011 \mathrm{com}$ a saída de quase a totalidade de pessoas do local, mas contando ainda com resistências que só o deixaram definitivamente em fevereiro de 2013 quando da última determinação judicial de desocupação.

Esse período de pesquisa na Vila Itororó serviu como base para a criação de Cidade Submersa ${ }^{3}$ e atuou como um grande dinamizador das reflexões e criação do grupo. A pesquisa trouxe em si noções e desafios importantes para que pensássemos a memória e o patrimônio como materiais passíveis de serem teatralizados e a 
compreensão da necessidade de revermos os papéis que eles desempenham hoje na nossa sociedade.

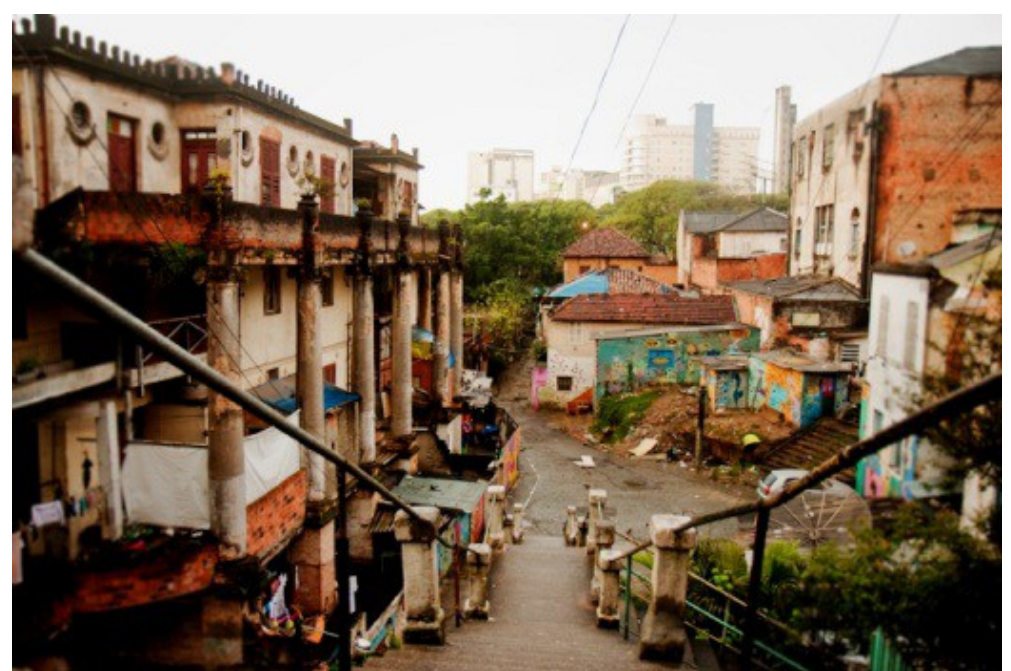

Figura 1 - Panorâmica da Vila Itororó vista da Rua Martiniano de Carvalho em 2009. Fotografia: Alícia Peres

\section{O projeto "Desassossego - suas outras memórias"}

Com o projeto "Desassossego" queríamos falar de memórias e desmemórias, da dificuldade de se consolidarem processos de construção de identidade na cidade de São Paulo devido a sua intensa dinâmica de construção, destruição e reconstrução, bem como dos fluxos e grandes deslocamentos cotidianos e projetos questionáveis de urbanização que se sobrepuseram ao longo do século passado e do atual. Queríamos tratar da nossa necessidade de identificar as características de uma possível cultura paulistana em atrito com os imperativos alienantes da paisagem urbana.

Ao encontrar a Vila Itororó, compreendemos que ela condensava muitas das características que havíamos cercado enquanto discurso poético. Primeiramente, deparamo-nos com diversas gerações vivendo num mesmo espaço, o que gerava distintos depoimentos e um rico arcabouço de memórias orais. Além disso, encontramos diversas camadas arquitetônicas num mesmo lugar, que sintetizavam momentos históricos distintos da cidade, ao mesmo tempo em que traduziam uma tensão presente na metrópole: a possível preservação de um patrimônio histórico tombado em choque com um projeto de revitalização que não previa as vidas que ali se construíram por décadas. O projeto corrobora com interesses de especulação 
imobiliária e uma proposta cultural fetichista, alienada das histórias construídas por gerações das mesmas famílias naquele lugar.

A Vila Itororó então constituiu nosso eixo de pesquisa de campo para o projeto "Desassossego", que incluía o processo de criação do espetáculo Cidade Submersa, e também uma série de ações culturais e políticas junto à Associação de Moradores e Amigos da Vila Itororó - AMAVila, ao Serviço de Assistência Jurídica da USP SAJU, e ao Coletivo Mapa Xilográfico, que realizou trabalho de natureza similar ao nosso na região do Bexiga, incluindo atividades na Itororó.

Durante essas ações, questionávamo-nos: o patrimônio histórico está separado do patrimônio humano? Que interesse pode haver em se preservar unicamente a arquitetura de um edifício histórico, quando a história de vida das famílias que viveram naquele lugar por décadas será apagada e esquecida? Por que o projeto de revitalização da Vila Itororó não incluía a vida de seus moradores, que também compõem a história local?

Convencidos de que o foco de nossa pesquisa estava nas memórias de vida dos moradores de São Paulo - muitas vezes contraponto ao discurso da história oficial e com o objetivo de trazer à tona uma perspectiva muitas vezes silenciada ou ignorada na elaboração de projetos urbanísticos -, iniciamos uma coleta de depoimentos de moradores da Vila Itororó, e também de um morador da Vila Maria Zélia, vila histórica na região do Belém. Vila Maria Zélia também possui o dilema de preservação de seus edifícios públicos tombados (escolas, armazéns etc.) e a avançada deterioração deles. Esses depoimentos foram registrados em áudio, alguns em vídeo, e mais tarde compuseram a dramaturgia de Cidade Submersa.

Passávamos a compreender a memória como elemento dinâmico e social, um dado a ser vivenciado no cotidiano e nas relações que estabelecemos em espaços de convivência, podendo também exercer, inclusive, um papel provocador para nossas ações no presente, na medida em que nos apropriamos de experiências vividas e compartilhadas e as contrapomos como conhecimento no tempo presente. Ao invés de encararmos a memória como entidade relegada ao passado ou um objeto a ser contemplado de maneira distanciada e nostálgica, nosso ponto de vista foi o de 
enxergar os fios que ela começa a tecer no passado e que se manifestam no presente, tornando-se um elemento dialético para a compreensão de nossa atualidade histórica.

\footnotetext{
O tempo da memória é o presente porque é no presente que se constrói a memória - a memória não se constrói no passado, se constrói no presente. Em segundo lugar, porque são às necessidades do presente que a memória responde, não às necessidades do passado nem às do futuro, embora muitas vezes, retoricamente, seja apresentado assim. Finalmente, os usos todos da memória são usos no presente - tradição só existe no presente das sociedades. (MENESES, 2007, p. 32).
}

\section{Cidade Submersa}

Com o objetivo de elaborar esteticamente essas memórias como testemunhos vivos das pessoas e expressões de seu tempo histórico, utilizamos uma técnica de trabalho teatral chamada mímesis corpórea, sistematizada pelo grupo de teatro $\mathrm{LUME}^{4}$. A técnica consiste na observação de ações físicas e vocais das pessoas entrevistadas, na posterior edição deste material, recriação das ações observadas por parte dos atores e elaboração destas enquanto material cênico. Com esta técnica, a coleta de material não se apoia exclusivamente na transcrição e edição do registro, mas também na memória dos atores que estiveram em contato com as pessoas entrevistadas. Os atores são pesquisadores que realizam um treinamento para uma observação aguda, que abarca a atenção de diversos aspectos da pessoa entrevistada simultaneamente. Dessa maneira, o material colhido nesses encontros abrange para além do discurso verbal, as informações do corpo - os gestos, as intenções, qualidades da fala, ritmo, pausas, altura da voz - além da observação das emoções e afetos que vêm à tona no momento do depoimento, tanto na pessoa entrevistada, como no próprio pesquisador.

Em tal perspectiva, o corpo do ator também se torna um suporte de memória, no qual irá ocorrer uma recuperação e recriação das ações físicas e vocais observadas, que unidas aos depoimentos transcritos e editados, geram um documento cênico a ser apresentado ao público, buscando instaurar um ambiente estimulante e propício para emersão de leituras, interações e reminiscências dos espectadores. 
Esses procedimentos de pesquisa, muito próximos de metodologias da história oral, requerem uma postura particular do "pesquisador", devido à natureza e objetivos do próprio trabalho teatral. Percebemos, por exemplo, que o convite a uma "entrevista" suscitava uma postura demasiado formal nas pessoas abordadas, e como consequência, elas não se abriam para relatar suas histórias de forma mais espontânea. Algumas ficavam desconfiadas e limitavam-se a dizer pouco, pois a Vila Itororó já possuía um histórico de pesquisadores que se aproximaram, colheram fotos, vídeos e depoimentos, e nunca mais voltaram, nem deram uma devolutiva do material que pesquisaram à comunidade. Por esse motivo, nosso convite era para uma "conversa", um "café" ou algo similar, para assim estabelecer uma relação mais informal e descontraída com os moradores entrevistados e colher um material potente tanto discursivamente quanto afetivamente, como é o caso do depoimento do Sr. Edélcio, o "Seu Dedé”, morador da Vila Maria Zélia:

Isso aqui é como se fosse, no fundo, é a essência da vida da gente. E ver isso tão, tão assim judiado... Ma Deus é pai que eu vou ver isso restaurado. O que o tempo e o homem destruiu. É um disleixo cum a história, cum patrimônio nosso né? Nunca tem dinheiro pá nada. Então foi largando, foi largando, foi ficando e ó aí ó o estado que ficô. Por falta de interesse mesmo público ${ }^{5}$.

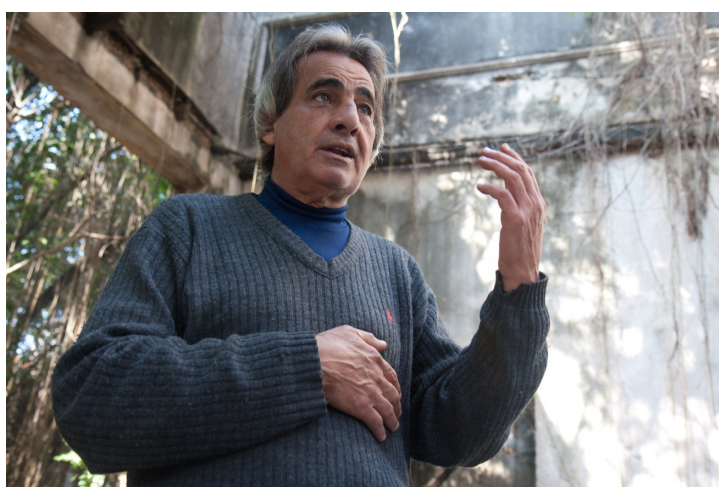

Figura 2 - Edélcio (Seu Dedé). Fotografia: Alícia Peres

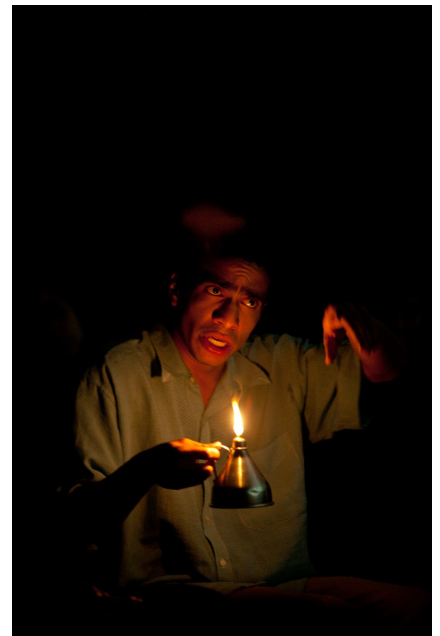

Figura 3 - Jorge Peloso representando Seu Dedé em Cidade Submersa. Fotografia: Alícia Peres

Ao mesmo tempo em que levantávamos o material por meio de depoimentos, o tema que havíamos nos proposto representar - a memória e identidade na cidade de São 
Paulo - exigia que abarcássemos um discurso mais amplo do que apenas o do testemunho privado. Necessitávamos problematizar essas memórias de vida, confrontando-as com outros vetores operantes na metrópole, de forma a podermos falar de memória numa escala mais ampla, contrapondo o privado e o público, o micro e o macro.

Para tanto, trabalhamos com improvisações teatrais a partir do mote da relação entre dois personagens idosos, amigos de infância: um com Alzheimer, que busca incessantemente reencontrar sua casa na cidade, mas não consegue mais reconhecê-la, e outro que não fixou raízes em nenhum lugar, e tenta ajudar inutilmente o amigo em sua busca. No desenrolar das cenas geradas com estes dois personagens, sintetizamos metaforicamente conflitos com os quais nos deparamos ao longo da pesquisa: a violência da velocidade das mudanças na metrópole, as desmemórias e a impossibilidade de reconhecer o seu lugar na cidade de São Paulo, a especulação imobiliária como um forte vetor de apagamento dos referenciais identitários na cidade, a perda dos elos comunitários, o esvaziamento do espaço público, as políticas públicas como protagonistas de um processo de gentrificação, entre outros.

Apresentamos aqui um trecho do texto final de Cidade Submersa, no diálogo entre os personagens Eliseu, com mal de Alzheimer, e seu amigo Virgílio:

\section{Virgílio}

Caso você esqueça, eu sou o Virgílio, o pé de vento e você é o Eliseu, cabeça de vento! (pausa) Quer dizer que não tem mais o riozinho?

Eliseu (de costas, olhando para o público)

Tem não.

\section{Virgílio}

E o campinho?

\section{Eliseu}

Também não.

Virgílio

O armazém da dona Cida?

Eliseu

Também não tem.

Virgílio 
O clube?

\section{Eliseu}

Derrubaram e fizeram um estacionamento.

\section{Virgílio}

Mas não tem mais nada!!?

\section{Eliseu}

Também, o que você quer? Já sei! Você quer tudo. É tudo seu. quer riozinho, armazém, campinho, clube, quem você pensa que é? Você é um desses que quer tudo! Compra, destrói e faz condomínio fechado, estacionamento, shopping center, arrasa com as nossas histórias e ainda quer se vender de bom moço! Quem o senhor pensa que é?

\section{Virgílio}

Eu sou $0 . .$.

Eliseu (interrompendo)

Não precisa responder! O senhor deve ser um desses laranjas, que vem na frente pra pesquisar o terreno, não é? E depois...depois vêm as britadeiras, os bate-estacas, as máquinas de terraplanagem... gentinha sem mãe, sem passado... sem lembrança... gente sem alma.

\section{Virgílio}

Mas...

\section{Eliseu}

Não tem mas nem meio mas... Vocês pensam que o dinheiro pode comprar até a alma da gente... Vocês... Vocês são uns...

Virgílio (interrompendo)

Eliseu, Eliseu... sou eu o Virgílio, o pé de vento, calma, calma.

Eliseu (acalmando-se)

Virgílio? Virgílio... Eu já ouvi falar esse nome em algum lugar. O senhor tá querendo me confundir? (reconhecendo) Ah! Virgílio? Desculpa! Desculpa Virgílio, é que às vezes eu me perco no labirinto da minha cabeça, dobro uma esquina, desço uma ladeira e vou me perdendo... Bem, eu tenho que ir embora pra casa... (pausa) Mas onde é que eu moro mesmo?

(Trecho extraído do texto do espetáculo Cidade Submersa, 2010.)

De forma fragmentária e constituído de depoimentos colhidos em campo, cenas com os personagens Eliseu e Virgílio e cenas independentes que retratam situações da metrópole, o texto teatral de Cidade Submersa é um documento artístico que concentra nossa pesquisa, experiência e discurso sobre o tema da memória na cidade de São Paulo. 
Assim como o documento escrito é apenas um suporte da memória de um presente histórico, o texto teatral é apenas um suporte para o acontecimento teatral. Por isso, para além do texto, a dramaturgia de Cidade Submersa é um registro mais amplo da problematização da memória a que nos propusemos. A dramaturgia abarca todos os elementos da cena - o texto, a luz, a música, os figurinos, os elementos de cena e, sobretudo, os atores, os quais ressignificam no presente da cena junto ao público a memória da experiência da pesquisa, que em cada apresentação reconstroem a narrativa de um tempo histórico junto ao público.

\begin{abstract}
Toda memória, diz Franco Ferrarotti, é uma experiência de comunidade, que nunca se efetiva em um vácuo social. Nessa ótica, quando se fala em perda da memória não deveria se tratar da perda de uma substância vulnerável, friável, frágil, que precise ser recuperada ou até depurada, mas tal perda deve ser entendida como perda dos elos comunitários. Esta, sim, é a perda efetiva. (MENESES, 2007, p. 26)
\end{abstract}

Então sendo a experiência teatral um acontecimento único e irrepetível, que se dá no encontro, sempre singular, de atores com o público, nossa proposta age na tentativa de estabelecer no momento da apresentação o gérmen para a socialização da memória e sua ressignificação no presente, como elemento de evocação da memória dos espectadores. Como exemplo, citamos o início de Cidade Submersa quando perguntamos aleatoriamente a alguém do público: "Que lugar mora em você?". O espectador ao responder elege e compartilha publicamente seu lugar de memória, acontecimento este que incita a todos os espectadores a buscarem em si suas próprias respostas, mesmo que não socializadas durante a apresentação.

A nossa necessidade de possibilitar a socialização de memórias evocadas durante a peça gerou um momento posterior ao das apresentações, no qual costumamos realizar uma conversa com o público, buscando efetivar este espaço de partilha de memórias, reflexões e impressões suscitadas pelo espetáculo. Criar este espaço do bate-papo após a peça se tornou cada vez mais necessário neste trabalho por construir uma instância social atualmente fragilizada nas relações que estabelecemos nos grandes centros urbanos, fortalecendo um âmbito coletivo de composição de sentidos. 
Cidade Submersa estreou em 23 de maio de 2010, ocasião em que levamos um ônibus com 40 moradores da Vila Itororó para assistirem, pela primeira vez, ao espetáculo. Desde então, segue realizando apresentações em distintos lugares do centro e da periferia da cidade de São Paulo, em cidades do interior e, mais recentemente, na Argentina. Ao longo desse período fortaleceu-se a nossa convicção de que a problematização da memória enquanto experiência coletiva no presente tem uma pertinência não somente na capital paulista, mas também em cidades menores e realidades aparentemente distintas da nossa, como no contexto argentino , fazendo-se necessário multiplicar esses espaços de troca e aprendizagem.

A cada apresentação de Cidade Submersa fazemos o exercício de disparar um processo que proporcione $\mathrm{o}$ encontro e $\mathrm{o}$ confronto entre as memórias representadas no espetáculo, as dos atores e as do público, problematizando-as frente aos processos históricos da cidade que nos atravessam cotidianamente. Esta foi a maneira que encontramos para estabelecer espaços em que a memória se ressignifica em atos de compartir, não mais como algo estanque no passado, mas fruto das relações que surgem a cada dia de apresentação. Dessa forma, tais espaços agem contra um contexto dominante que cada vez mais usurpa, desestimula e enfraquece este rito - o da partilha da memória e sua reflexão no presente, no qual a possibilidade do confronto com o outro gera um momento propício para reconstruirmos nossos referenciais de identidade.

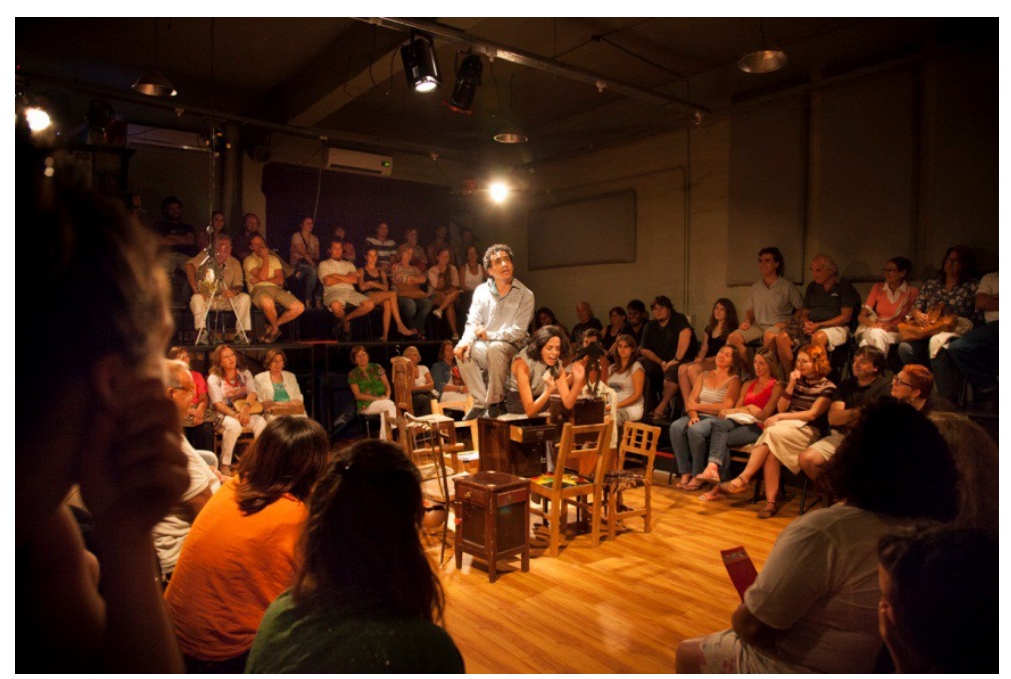

Figura 4 - Apresentação de Cidade Submersa no II Festival KnotsNudos em San Pedro, 


\section{Argentina em 2013. Fotografia: Alícia Peres}

\section{Notas}

(1) O IMPULSO Coletivo foi criado em 2007 com o objetivo de pesquisar práticas que potencializassem as capacidades corporais, vocais e criativas do ator, e de gerar uma expressividade distinta da usada no cotidiano, com base no treinamento promovido pelo grupo LUME Teatro - Unicamp. Além disso, tem como projeto o treinamento de ator em confronto com realidades de exclusão social, a formação de público e o campo temático entre a memória e processos de formação de identidade.

(2) Conselho de Preservação do Patrimônio Histórico, Artístico, Arqueológico e Turístico do Estado de São Paulo (Condephaat).

(3) A peça estreou em maio de 2010 com temporada no Espaço Cultural Casa das Caldeiras. Mais informações sobre o processo de construção e interação com a Vila Itororó em: Jorge Peloso de.Azevedo. $\underline{\text { A Cidade }}$ Submersa que encontramos na Vila Itororó; Jorge Peloso de Azevedo e Marília Gabriela Amorim Donoso,. Atitude: desdobramentos e confrontos do treinamento do ator no processo de criação do espetáculo Cidade. Submersa. PesquisAtor, n. 1, maio-out. 2012.; e, Marília Gabriela Amorim Donoso, O treinamento como processo de investigação do ator-criador

(4) Núcleo composto de atores-pesquisadores fundado por Luís Otávio Burnier em 1985, vinculado ao Instituto de Artes (IA) da Universidade Estadual de Campinas (Unicamp), com objetivo de desenvolver pesquisas sobre técnicas de ator. Entre as atividades realizadas em sua sede em Barão Geraldo estão: a realização de mostras de espetáculos, workshops e seminários de capacitação prolongados; intercâmbios culturais com a comunidade e demonstrações de processos de trabalho. Atualmente, o LUME é composto de sete atores e se tornou referência internacional para artistas e pesquisadores no redimensionamento técnico e ético do ofício de ator.

(5) Edélcio Pereira Pinto em entrevista concedida em junho de 2009.

\section{Referências bibliográficas}

AZEVEDO, Jorge Peloso de. A Cidade Submersa que encontramos na Vila Itororó, 2012 (inédito). Disponível. em: <http://impulsocoletivo.files.wordpress.com/2012/10/a-cidade-submersa-que-encontramos-na-vilaitororo.pdf>

CARVALHO, Dorberto Rocha; AZEVEDO, Jorge Peloso de; DONOSO, María Gabriela Amorim. Cidade Submersa. 2010 (texto do espetáculo - não publicado).

;DONOSO, Marília Gabriela Amorim. Atitude: desdobramentos e confrontos do treinamento do ator no processo de criação do espetáculo Cidade Submersa. PesquisAtor, n. 1, maio-out. 2012. Disponível em: <http://www.revistas.usp.br/pesquisator/article/view/36122> 
BENJAMIN, Walter. Magia e técnica, arte e política: ensaios sobre literatura e história da cultura. 7. ed. São Paulo: Brasiliense, 1994.

BURNIER, Luís Otávio. A arte de ator: da técnica à representação. Campinas: Unicamp, 2001.

DONOSO Marília Gabriela Amorim. O treinamento como processo de investigação do ator-criador. Dissertação de Mestrado em Artes, Instituto de Artes, Universidade Estadual Paulista São Paulo, 2008-2010. Disponível em: <http://www.athena.biblioteca.unesp.br/exlibris/bd/bia/33004013063P4/2010/donoso_mga_me_ia.pdf>.

MENESES, Ulpiano Bezerra de. Os paradoxos da memória. In: MIRANDA, Danilo Santos de. Memória e cultura: a importância da memória na formação cultural humana. São Paulo: SESC SP, 2007.

\section{Entrevista}

2009: Edélcio Pereira Pinto (não publicado).

\section{Créditos}

*Graduado em Licenciatura em Educação Artística, habilitação em Artes Cênicas, pelo Instituto de Artes da Universidade Estadual Paulista, São Paulo/SP, Brasil. É fundador, diretor e ator-pesquisador do grupo IMPULSO Coletivo. E-mail para contato: impulso.coletivo@yahoo.com.br.

**Mestrado em Artes, linha de pesquisa em Artes Cênicas, pelo Instituto de Artes da Universidade Estadual Paulista, São Paulo/SP, Brasil. Fundadora e atriz-pesquisadora no grupo IMPULSO Coletivo, desenvolve pesquisa na área de processos de criação, treinamento do ator e formação de público. 